AperTO - Archivio Istituzionale Open Access dell'Università di Torino

\title{
Selling cruises: gender and mobility in promotional brochures
}

\section{This is the author's manuscript}

Original Citation:

Availability:

This version is available http://hdl.handle.net/2318/1618762

since 2017-03-17T16:28:48Z

Published version:

DOI:10.1177/1468797616682615

Terms of use:

Open Access

Anyone can freely access the full text of works made available as "Open Access". Works made available under a Creative Commons license can be used according to the terms and conditions of said license. Use of all other works requires consent of the right holder (author or publisher) if not exempted from copyright protection by the applicable law. 
SELLING CRUISES: GENDER AND MOBILITY IN PROMOTIONAL BROCHURES

\author{
Alberto Vanolo \\ Nadine Cattan
}

\begin{abstract}
Leisure cruising combines movement and stativity in a particular tourist experience: users are supposed to enjoy very different activities, with the movement of the ship guiding them to their destinations. This paper analyses visual representations of gender and mobility in over 600 images collected from leisure cruise promotional brochures by taking advantage of a qualitative methodology and by focusing on narratives related to themes of pleasure, work, age, and contact with nature/culture. The results stress the presence of an implicitly masculine gaze, with complex and non-linear associations with the themes of mobility and immobility, which relates to visual narratives in a number of different ways, testifying to the multiple meanings that may be assumed by the idea, the practice, and the experience of movement.
\end{abstract}

\title{
Keywords
}

leisure cruises; mobility; gender; promotional brochures; advertisements; visual methodologies 


\section{Introduction}

This paper proposes an analysis of gendered representations of cruise tourism in promotional brochures produced by the cruise industry. The rationale at the basis of the paper is to contribute to critical tourist studies by developing critical dialogues, conversations and entanglements into the nature of power, discourses and representations in tourism, as suggested by Ateljevic et al. (2007; see also Bianchi, 2009). In this sense, leisure and tourism are addressed as 'predominantly cultural phenomena' (Aitchinson, 2006, p. 419), and specifically this paper aims at developing a critical reflection on the gendered gazes produced and reproduced through the promotional images of the cruise industry.

From a theoretical point of view, the analysis is grounded in debates on gendered mobilities and tourism, and it aims at questioning the dichotomy between mobility/empowerment and stasis/disempowerment that has been discussed in various contributions in the field of gendered mobilities (cf. Rose, 1993; E. Prichard, 2000; Johnston, 2001; Cresswell and Uteng, 2008). The thesis supported here is that, despite the abundant display of mobile and dynamic women in the promotional images of the cruise industry, it is possible to observe the persistence of various forms of a 'masculine gaze' (Mulvey, 1975; in the field of tourist studies see Pritchard and Morgan, 2000). According to the feminist literature, a masculine gaze consists in the presence of a visual apparatus which puts the spectator in a masculine subject position, with the figure of the woman as the object of masculine heterosexual desire. In this sense, promotional discourses in the cruise tourism industry contributes in reproducing cultural frames which are embedded in uneven power relations between female and male subjects.

It is just the case to mention that there is a long tradition in the critical analysis of the nexus between culture, gender and space in the spheres of leisure and tourism: more than 20 years ago, Bell and Valentine (1995) published the pivotal book Mapping Desire, focusing on the production of gendered space in daily life, and authors such as Kinnaird and Hall (1994), Anderson (1996), Duncan (1996), Aitchison (1999, 2001), Pritchard and Morgan (2000, 2005), and Pritchard (2001) explicitly introduced gendered spaces in tourist studies.

The conceptual premise is that since tourism is (also) a cultural phenomenon of gendered societies, tourism processes are gendered in their construction, representation, and consumption. In this sense, various lines of critical research have emerged over time in critical tourist studies in order to challenge current visible and invisible gendered power relations: from feminist studies in tourism employment, to Marxist, radical, and socialist feminist critiques of sex inequality in tourism; from post-structural feminist approaches to gender, tourism, and cultural relations, to the analysis of gender inequalities in tourism practices, such as sex tourism or gay tourism (Aitchison, 2009; Thurnell-Read and Casey, 2014).

In the field of post-structural feminist approaches, Sirakaya and Sonmez (2000), Pritchard and Morgan $(2000,2005)$ and Prichard (2001) have worked in the sphere of representations by analysing the nature of the images of women and men portrayed in tourist marketing materials. A key concept they mobilised is the male gaze (see Aitchison et al., 2002; Harris and Ateljevic, 2003; Degen and Wainwright, 2010; see also the classic contribution of Goffman, 1976). Altogether, this means that the imaginary of tourist promotion privileges the male, heterosexual gaze above all others. In this way, it tends to produce male tourism landscapes by placing women and non-heterosexual subjects in marginal and/or subaltern positions, for example by displaying women as sexualised passive bodies to be observed, desired, and consumed by heterosexual males (Waitt et al., 2008). In this sense, Gillian Rose argued that women are constituted as explicitly embodied: "women of all kinds are expected to look right, and to look right for a gaze which is masculine [...] Women's sense of embodiment can make 
space feel like a thousand piercing eyes [...] it is a space which constitutes women as embodied objects to be looked at" (Rose, 1993, pp. 145-146).

This paper aims at contributing to this line of research by introducing a specific dimension to the investigation, that is a focus on representations of mobility. It has to be pointed out that in this paper 'mobility' and 'movement' are used as synonyms, as are 'immobility', 'stasis', and 'fixity' (cf. Cresswell, 2010). A number of studies, particularly in human geography, have emphasised how mobility practices and discourses are highly gendered, particularly due to powerful dominant discourses about 'man's world, woman's place' (Ganser, 2009). The premise, particularly discussed by Massey (1994) and Domosh and Saeger (2001), is that the production of the mainstream dichotomy public/male vs private/female has been historically connected to the ideology of the home as the 'feminine sphere' and hence to the limitation of women's mobilities. In this perspective, mobility has been also conceived in feminist theory as a political strategy: according to Massey (1994, p. 11), female mobility "pose[s] a threat to a settled patriarchal order."

Quite obviously, gender is just one among the many positionalities affecting mobility. Class, race and age, for example, highly influence a woman's mobility and her presence in public space. But, what is more crucial for this paper, the conceptual opposition between home/stasis/disadvantage and travel/mobility/empowerment is fragile. Firstly, the home is a dynamic site of social relations, a site of unrestful differences, and hence not a site of immobility (Clifford, 1997). Secondly, as it will be argued, mobility is not inherently empowering (Domosh and Saeger, 2001), and stasis is not necessarily coupled with the absence of mobility, as testified by the paradigmatic case of cruising.

The aim of this paper is twofold: on the one hand, the paper explores the gendered positionalities proposed in the promotional discourses; on the other hand, it questions the roles of mobility and fixity in building these discourses. In fact, in the case of leisure cruises, ideas of mobility and immobility play an important role in the construction of the tourist experience. For example, a well-known idea regarding cruises is that people move and visit places while performing other actions, including actions implying the stativity of the body (for example sunbathing) within the 'tourist bubble' constituted by the ship (Jaakson, 2004; Schmid, 2008). This paper argues that this narrative is highly gendered: the cruise ships displayed in the promotional brochures operate as mobile sites for the construction, legitimation, and reproduction of uneven gendered positionalities. This paper argues that a male gaze is embedded in the promotional discourse, and representations of mobility and fixity are meaningful elements in the construction of the gendered narratives of cruise tourism in a number of different ways.

To explore the above-presented arguments, the paper is organised as follows: the succeeding section introduces cruise tourism. This is followed by a description of the methodology adopted in the analysis. Section 4 presents the main results of the analysis by focusing on four themes. The main findings are summarised in the concluding section.

\section{Some notes on cruise tourism}

Broadly speaking, cruise tourism is a form of leisure where the voyage itself, the ship's amenities, and the daily on-boat activities are part of the experience, as well as the activities performed in ports of call and off-board excursions. Transportation is hence not the main purpose, as cruise ships operate mostly on routes that return passengers to their originating port.

There is relatively little critical literature on cruises in social sciences (Berger, 2004), and according to Hasty and Peters (2012), the ship is a largely forgotten space in geography. The 
literature mainly focuses on the characteristics of the cruise industry (Klein, 2002; Weaver, 2005a and 2011; Clancy, 2008; Terry, 2011), the politico-cultural characteristics of cruise experiences (Weaver, 2005b; Atkinson and Blandy, 2009; Vogel and Oschmann, 2013), and the management of cruises (Gibson, 2006; Papathanassis et al., 2012; Vogel et al., 2012). Contributions on the relations between gender and the cruise industry have only focused on specialised queer cruises (see Puar, 2002; Hughes, 2006; cf. Weaver, 2011) and the different working conditions for males and females (Chin, 2008).

In 2015 there were 53 cruising companies operating worldwide. Most of them have headquarters in the western hemisphere: 48 of the 53 companies are based in North America or Western Europe (cf. Dowling, 2006; Rodrigue and Notteboom, 2013). The geographical concentration of cruise companies reflects the distribution of the passengers: according to the Cruise Lines International Association (CLIA) data for 2013, 60.2\% of cruise passengers were from North America and $27.0 \%$ from Europe; hence, a mere $6.7 \%$ of cruise passengers came from Asia and $6.2 \%$ from the rest of the world. All these details are important for emphasising that, given the high geographical polarisation of cruise companies and tourists, the promotional materials that have been analysed in this paper are arguably embedded in 'Global North' cultures, dreams, lifestyles, and aesthetic perspectives. From the point of view of advertising, the cruise sector definitely appears as a global industry operating within complex transnational networks, but with a very specific audience in mind: despite the high variety of cruises targeting different tourists (for example in terms of wealth, from luxury or basic cruises), the visual apparatus mobilised in the brochures mostly targets white, Western and middle class (or wealthy) consumers (and heterosexual, as it will be argued).

An interesting cultural trait of cruise tourism is specifically the role of mobility. In a strict sense, it is arguably impossible to be literally immobile during a cruise, because even if the body is static, the ship is generally moving, providing the palpable feeling of travelling, which is, for many people, definitely enjoyable. In this sense, as it will be discussed, many promotional images display apparently static men and women, 'doing nothing', sunbathing or looking at the sea. But the apparent stasis of the body does not mean doing nothing: sunbathing, reading a book, observing the landscape or drinking are active actions and tourist performances, despite the limited amount of bodily dynamism they require (Haldrup and Larsen, 2010; see also Weaver, 2005a). There are, however, very different cases: some cruises are more or less explicitly proposed for elderly people, emphasising relaxed activities and/or playing with ideas of nostalgia (for example many cruises proposed by Cunard, Deilmann and Fred Olsen), while other ones target young people, proposing highly dynamic experiences (Royal Caribbean); some cruises target rich tourists seeking elegant, relaxed and luxurious experiences (Holland America, Celebrity, Crystal), while other cruise lines propose more 'exotic' (in the mainstream Western sense of the expression) or 'adventurous' experiences (Princess, Un-Cruises). Generally speaking, major companies, such as Carnival, Royal Caribbean and Norwegian Cruises, highly diversify their cruises in order to reach different targets (cf. Dickinson and Vladimir, 2007; Vogel and Oschmann, 2013). In most cases, the ships, shipboard attractions and shore excursions are designed to activate passengers, particularly by offering them the possibility to engage in a number of activities, from highly dynamic ones (such as water slides) to relatively static ones (sitting in a hall and watching a show). The high variety of different cruises targeting different audiences suggests that cruise lines and cruise tourists are not homogeneous entities. However, this paper does not engage in the analysis and classification of different discourses produced by different companies, but rather it addresses cruise tourism as a global and variegated promotional discourse, as discussed in the next section. 


\section{Methodology}

The research is based on a visual analysis of images from cruises brochures. Visual materials from brochures have been largely used as secondary sources in tourism research (Jokela and Raento, 2012). It is just the case to stress that recent researches in the field are grounded in relational perspectives, refusing the old, positivist idea that images offer pure evidences of truth as sort of mirrors reflecting or transcripting reality (cf. Rose, 2012; Scarles, 2010). In this sense, Scarles (2004) propose important reflections on the role of promotional brochures in producing 'mediated fantasies' and imaginary landscapes of pleasure embedded in different ideologies. According to author, in fact, the brochure imagery encourages individuals to place themselves within the image and to enact the roles presented on the brochure page: "subconscious invitations and messages of 'it could be you' encourage immersion of the self within the frame of the image, as the camera lens becomes the eye of the reader" (Scarles, 2004 , p. 46). It is precisely in this sense that it is possible to conjugate feminist perspectives with critical tourist analysis, as the 'it could be you' suggested by Scarles (2004) implicitly privileges masculine perspectives.

According to the literature (Dickinson and Vladimir, 2007; Kwortnik and Rand, 2012), and in line with discussions we have had with two tour operators, the promotion of cruises still takes place largely through the printed brochures distributed to tour operators and travel agencies. These brochures are also widely distributed in digital formats (usually pdf files) on websites and through promotional DVDs. For the purposes of this research, printed and electronic versions of the promotional brochures were collected through travel agencies and from the Internet: specifically, it was possible to obtain promotional brochures for 51 out of the 53 cruise lines (it has been impossible to obtain the promotional brochures of the two Finnish companies Birka Line and Kristina Cruises). It should be noted that, in some cases, specific thematic cruises are organised by companies which rent entire ships for limited periods of time. Hence, for example, it is possible to find on the Internet specific cruises targeting gay customers, for example Atlantic All-gay Cruises (http://atlantisevents.com). This study does not consider these offers, as it focuses exclusively on the promotional brochures provided directly by the cruising companies.

Some of the cruise lines provide relatively small brochures describing their services, while others publish several brochures focused on different destinations and potential customers, for example cruises for young people and cruises for families. It was decided to collect all of the brochures available for each cruise line for the 2014-2015 period. While some brochures were relatively small (around 30 pages), others were highly detailed (over 300 pages).

The images to be analysed were extracted from the brochures on the basis of their fulfilment of two criteria:

- Images have to include at least one person or a part of a human body (for example, a hand or a leg). The analysis of gendered representations needs, in fact, the presence of human bodies, and therefore images that did not feature people (such as images of landscapes) were discarded.

- Images have to occupy at least one third of a page in the brochure. This criterion was introduced in order to reduce the number of images to be analysed from the large volume of images presented in the brochures and to focus on images that were supposed to be 'meaningful' and 'important' -in the eyes of advertisers, at least.

The resulting sample was made up of 643 images. This equates to around 13 images per cruise company, on average. However, there is high variance in the distribution, which ranges from a 
minimum of 3 images (in a single case, relative to a small company) to a maximum of 44 images for a single company.

The main methodology used in this study is a qualitative analysis of visual data (SatherWagstaff, 2012), integrated with some insights from a quantitative content analysis, which constituted what could be called a preliminary phase of the analysis. In fact, as will be described below, the research has firstly been developed by taking advantage of traditional content analysis, and then the analysis has been performed by mobilising a qualitative methodology.

Content analysis is a quantitative form of analysis carried out through the process of deriving meaningful descriptors for images (Pritchard, 2001; Rose, 2012). Specifically, the 643 collected promotional images have been observed in detail and described textually through the association with keywords describing the content of the image; for example, in the case of a woman sunbathing, keywords such as 'woman', 'static', 'sunbathing', 'young', 'on board', 'alone', 'outdoor', etc. were used. The keywords have then been merged (in order to reduce their number) and analysed by using simple statistical frequency analysis.

Many of the limits of this methodology have become increasingly clear as the research has developed: it resonates with a positivist framework, implicitly assuming pre-given categories and presenting them, also in the use of the language of numbers and percentages, as selfexplanatory social facts, mobilising images as 'evidences' (cf. Banks, 2001; Scarles, 2004, 2014). Moreover, given the high variety of cruise tourists, cruise discourses, and cruise activities, average percentages run the risk of obscuring important information on the social construction of gendered discourses. At the same time, it has to be stressed that the performing of the content analysis produced meaningful outcomes; firstly, it allowed us to perform a first exploration of the data, providing inputs for successive qualitative elaborations; secondly, testing the limits of this methodology can be considered, somehow, a research outcome in its own respect; ultimately, considerations about the statistical distribution of specific visual contents allowed us to better perceive the recurrence of particular elements and the insistence on particular frames and tropes in promotional discourses.

The second phase of the analysis took advantage of a qualitative discourse-centred methodology, particularly by following the indications provided by Sather-Wagstaff (2012). In line with a diffused framing of social sciences, discourses are intended as verbal and nonverbal narratives, including those developed through the use of visual materials. In this sense, the images have been firstly coded by associating them with short sentences, brief comments, and other textual information. This process, which looks quite similar to the one performed in the content analysis, has been performed with a more qualitative and interpretative attitude: the coding has not been aimed at reflecting the actual content of the image, but rather to interpret them, particularly in relation to ideas and theories emerging from the exploration of the literature on gender, tourism and mobility, keeping also in consideration the feelings perceived by the researchers (cf. Pink et al., 2004, Scarles, 2010). To put it differently, the coding has not been limited to the iconic dimension of the images (the direct relation to what they represent), but also to their interpretation (their indexical and symbolic dimensions: Sather-Wagstaff, 2012), by mobilising the interpretative competences and sensibilities of the two researchers. Images perceived as 'similar' (both in terms of meaning and content, in relation to issues of gender) have been merged and commented on together. This process has been made easier by building on the coding experience of the content analysis.

The codes derived from the qualitative analysis have then been themed, grouped, and reconstructed in order to produce a more limited number of discrete categories, and precisely the four categories of 'pleasure', 'work', 'age' and 'contact' with nature and culture. These categories have then been used in order to formulate explanatory frameworks, that is, to 
interpret the underlying social processes and the consequent positionality of gendered subjects in relation to mobility and stativity.

\section{Selling Cruises}

\subsection{Pleasure}

The first category concerns the discourse on pleasure. Taking part in a cruise generally implies the expectation of a certain amount of pleasure, where - as mentioned earlier - different cruises, targeting different audiences, insist on different, and even competing, imaginaries of pleasure (Hung and Petrick, 2011). Focusing on the relation between pleasure, gender, and movement, there are at least two broad categories of discourses.

First, a certain number of images - actually, the majority, according to the content analysis portray relatively static bodies, with people engaging in some sort of enjoyable experience. A typical example is the one of Figure 1. It echoes the thesis proposed by Berger (2004), who describes being on a cruise as a kind of regressive experience: on cruise ships we experience the same kind of unconditional love we are supposed to have experienced when we were children, as the staff are trained to be friendly and accommodating, and stewards and their assistants appear to be happy to satisfy any needs we may have (see also Jaakson, 2004). It is not a coincidence that a number of images (about $20 \%$, according to the content analysis) show members of staff, as it will be discussed later.

\section{Figure 1 - Stativity and pleasure}

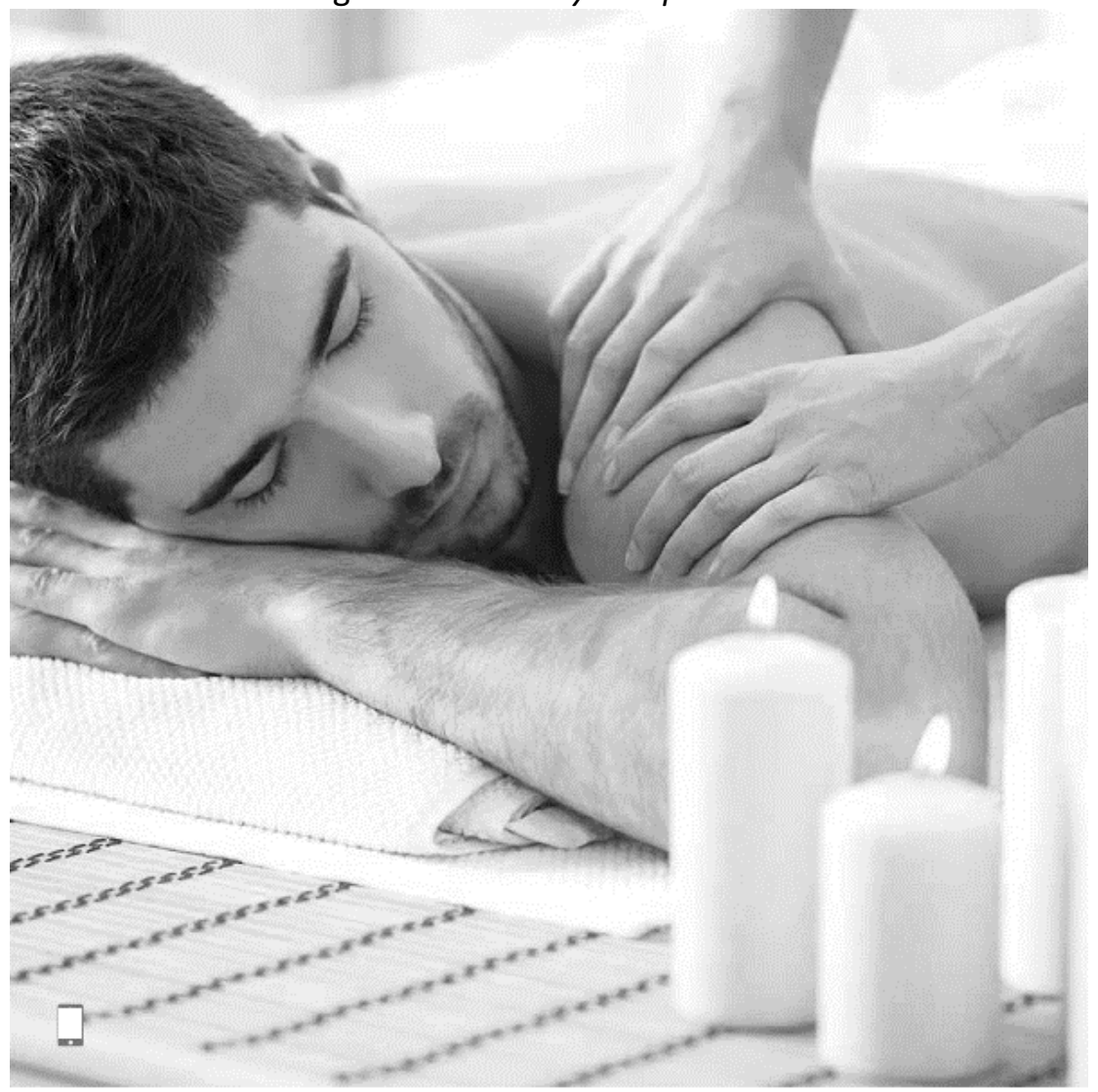

Source: Pullmantur Cruises promotional brochure 
There are many examples of images showing passive and static bodies as in Figure 1, including people lying on couches and beds, sunbathing, relaxing in swimming pools (not swimming), etc. A typical symbolic element introduced in the images in order to build narratives of pleasure and relaxation is the glass of wine. In terms of content, it has to be noted that one image out of four shows people eating and drinking. Of course, drinking and eating are active actions involving movement and agency, but in many cases glasses of wine are merely used to accompany static bodies in order to evoke relaxation and pleasure. Figure 2 shows a typical image, that is, a heterosexual couple drinking on the deck of a ship. Images of static people enjoying food and wine are transversal to all the companies, regardless of their ideal target: from luxury to basic cruises, from the ones destined to elderly people to the 'multigenerational' ones, all the brochures present a wide sample of pictures portraying people eating and/or drinking.

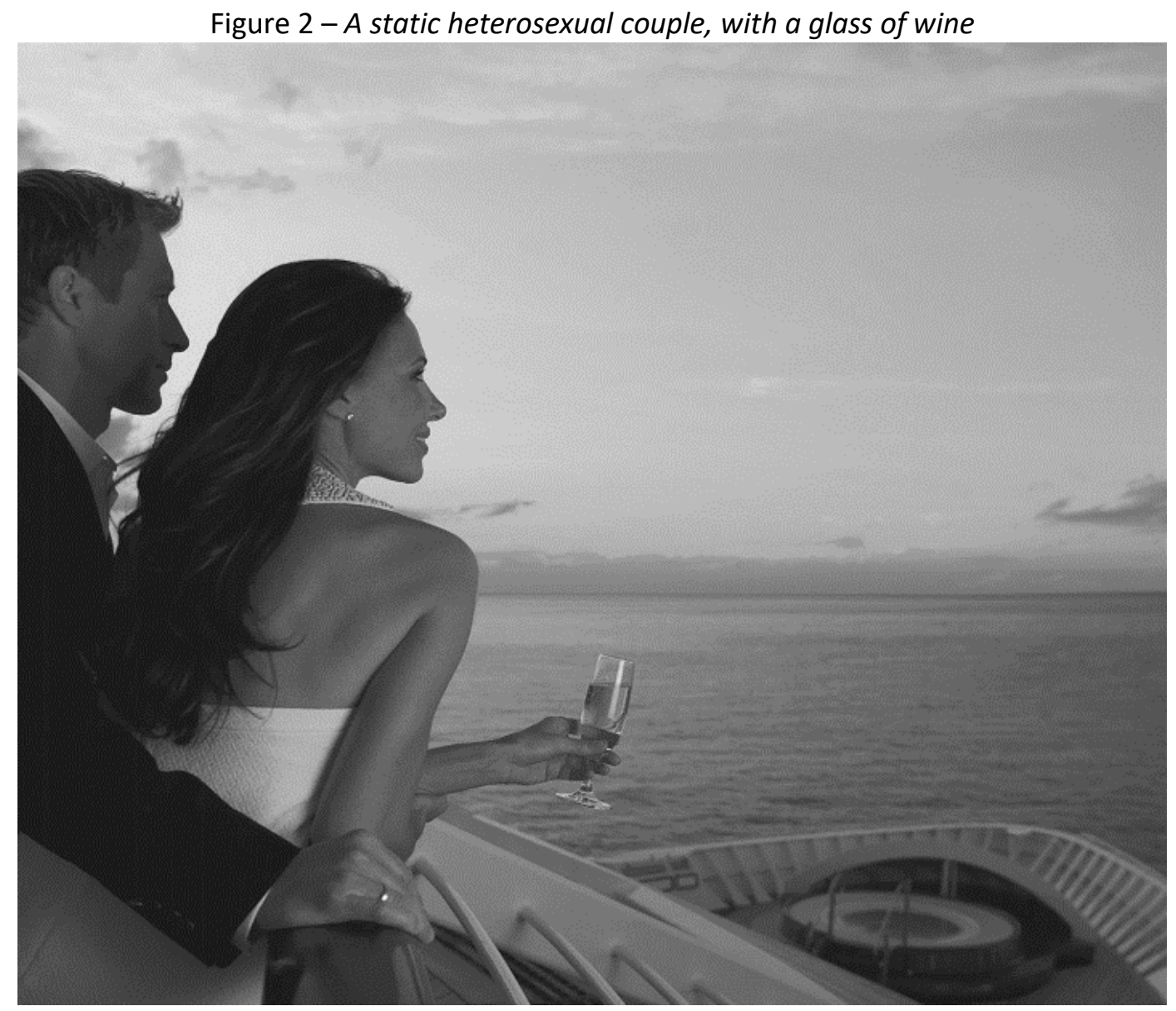

Source: Seabourn Cruise Line promotional brochures

A different discourse relates to images of people performing dynamic activities, such as dancing, swimming, snorkelling, or playing sports. This kind of representation is typically mobilised in order to promote cruises for young people, but there are meaningful exceptions (see later). Figure 3, for example, shows people training in a gym while looking at the deck of the ship and the sea. In terms of mobility, the picture is somehow paradoxical, because the exercise bike simulates the movement of a bicycle while keeping the body stationary, but the body is actually travelling because of the movement of the ship. 
Figure 3 - Stationary and travelling bodies training in a gym

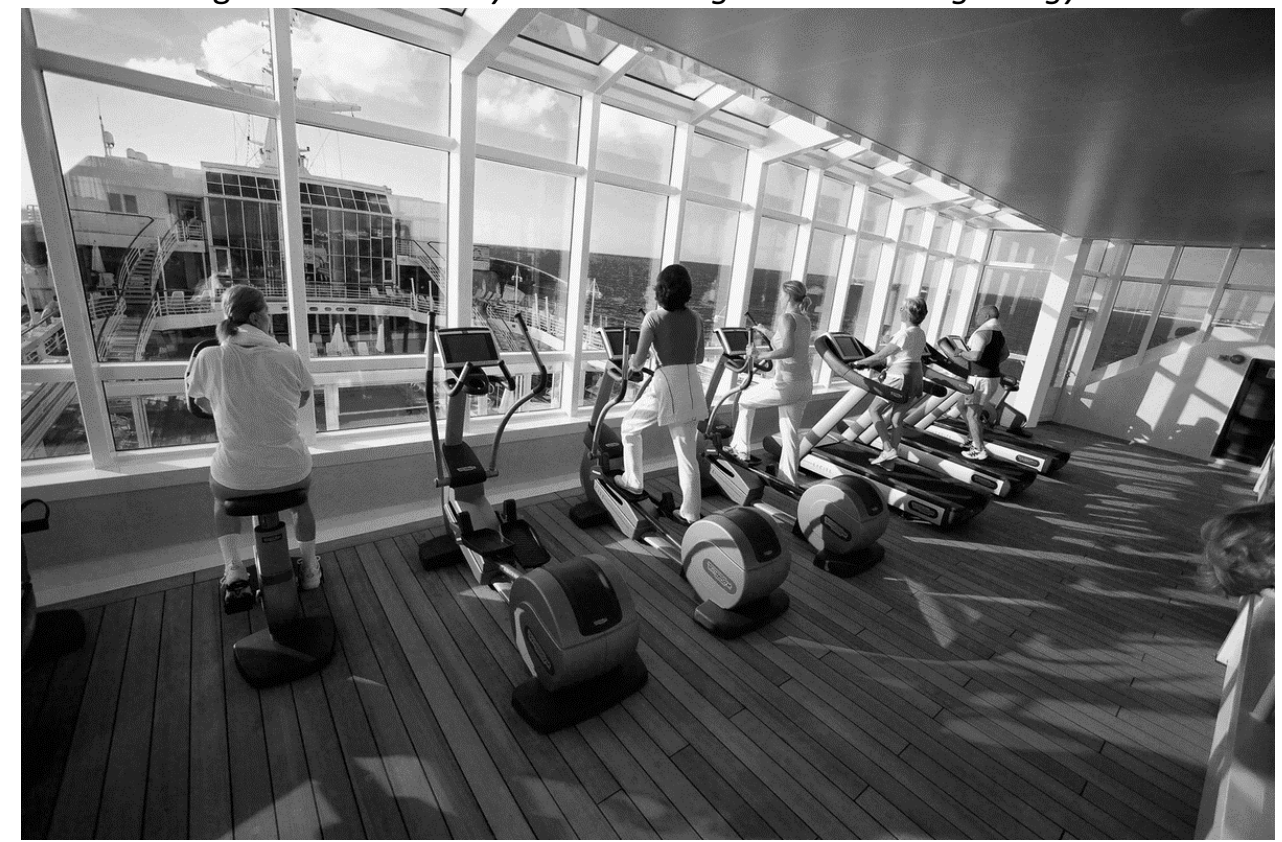

Source: Hapag-Lloyd Cruises promotional brochure

All these representations are gendered and sexualised in many complex ways which ultimately reproduce a male gaze. On the one hand, most of the images explictly represent, and hence they naturalise, heterosexual subjects and sociabilities (cf. Frohlick and Johnston, 2011). More than one third of the images resonates with the composition of Figure 2: a male and female subject in an intimate situation, for example looking romantically at the sea. By taking inspiration from Iris Young's pivotal analysis of female body experiences and performances (Young, 2005), it can be observed how the stativity of the bodies is a meaningful element of the visual narrative: the immobility of two bodies next to each other suggests intimacy. In this sense, masculine closeness is generally avoided: masculine groups generally include more than two people (in order to avoid looking like gay couples) and with bodies in movement, building a narrative of 'buddies having fun'. Differently, images displaying body contact and intimacy between women are more common, supporting the hypothesis that the subject which is supposed to look at the image is male and heterosexual and hence - as suggested by Gill (2009) in her analysis of the ideal-typical figure of the 'hot lesbian' in advertising - he may not be disturbed, or he may be even attracted, by women in intimate situations (cf. Connell, 2005). The presence of a hegemonic male gaze is also evident in the sexualisation of images of female bodies. As discussed previously, according to feminist critical literature (see for example Arend, 2014), the masculine gaze operates by transforming feminine subjects into kinds of sexualised objects to be observed and visually consumed, specifically through the gazes of the photographer and the reader. This visual composition typically occurs in advertising, and cruise advertising makes no exception. Promotional images displaying a single human body generally present a feminine body, and more precisely a good-looking and sexually attractive one. The sensual women is generally static, literally as an object.

There are, however, some exceptions. This may be the case of images showing immobile male subjects staring at women walking or swimming. In these cases, traditional associations between power and mobility are subverted: the main function of the mobile subject, which is the woman, is 'to be seen' by the static man in the image. And, more subtlety, both the man and the woman seem to enjoy their roles, further naturalising the uneven relation between genders. 


\subsection{Work}

As anticipated, images of the cruise staff are important elements in building the discourse about 'care': pictures of elegant ship captains, smiling waiters, cleaners, chefs, bartenders, and masseurs abound in the pages of the brochures. These subjects are always displayed in dynamic postures, for example performing actions such as pouring wine or cooking. What is evident in the images is the abundance of stereotypical divisions between masculine and feminine jobs.

A large body of feminist literature has emphasised how feminine works are typically and stereotypically associated to care and, more broadly, to emotional labour (see for example Rose, 1993; Cameron and Gibson-Graham, 2003). This stereotype is, to some degrees, also diffused in the promotional images of the cruise industry, often in relation to different forms of mobility and immobility: typically, while the client being cared for is immobile, the female labourer moves and carries out various duties (Figure 1). In this framework, images displaying physical contact between the body of the client and the body of the worker (typically a masseur, as in Figure 1) always display a female worker, irrespective of the client's gender, testifying to the presence of an implicit masculine perspective. This is common to all cruise lines, regardless of the typology of cruise proposed.

Conversely, feminist literature emphasises how stereotypical ideas of professionalism, competence, and control involve ideas of masculinity (cf. Connell, 2005; McDowell, 2005). In this case, different cruise lines show different attitudes. For example, the stereotype is reproduced through images showing male captains reassuring female customers (Figure 4), images associating the solidity of a ship to men's work, and images showing sophisticated wine experts analysing bottles to be proposed to clients.

Figure 4-Masculinity as safeness, reliability, and professionalism

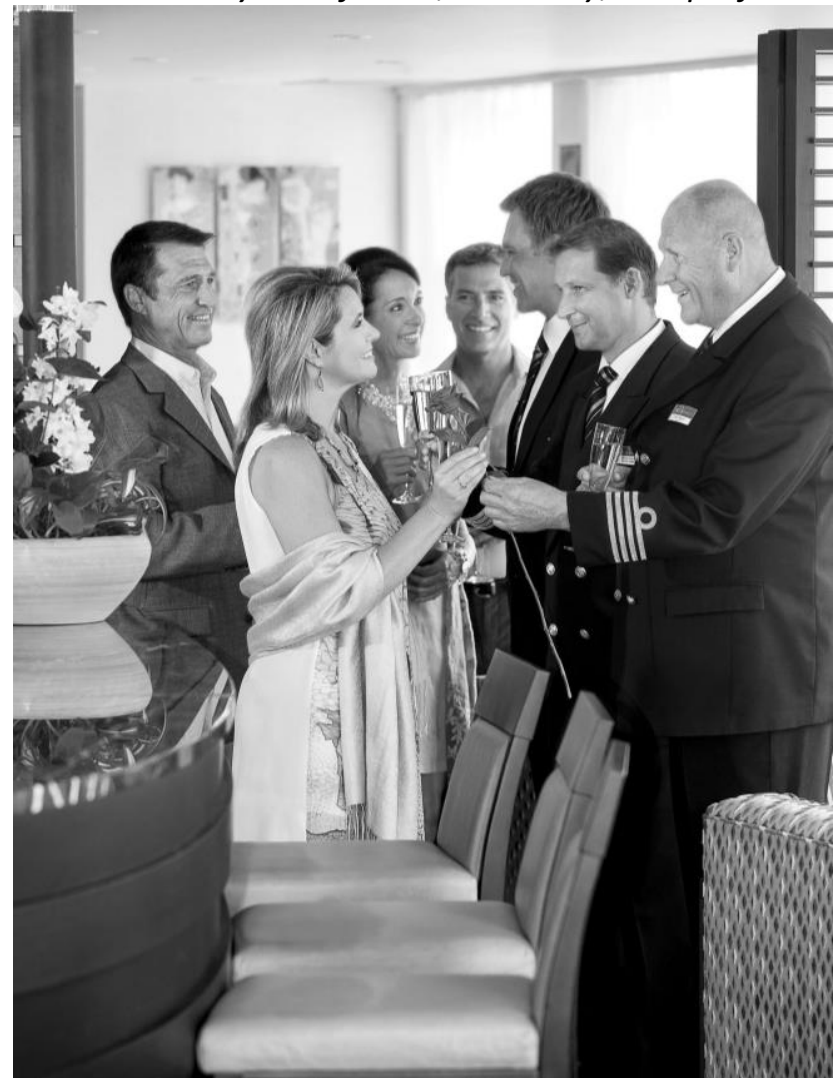

Source: AmaWaterways promotional brochure 
But there are also rare examples of counter-narratives presenting women performing jobs requiring expertise, precision, and authority, that is, skills usually attributed to men in the images. This is the case of images proposed by Transocean Tours, MSC and Hapag-Lloyd, three European-based companies. An example is presented in Figure 5, portraying two women, dressed in navy uniforms (their ranks are displayed on their shoulders) which are planning a route using a compass (a technical instrument, a symbol of a technical culture). According to feminist literature (Arend, 2014), and to critical literature in social sciences more in general (see for example the classic work of Boltanski and Chiapello, 1999), this counter-narrative may be interpreted not just as a progressive move away from patriarchal imageries, but as the mere incorporation of feminist discourses in advertising in order to accommodate a 'new spirit of capitalism' (Boltanski and Chiapello, 1999).

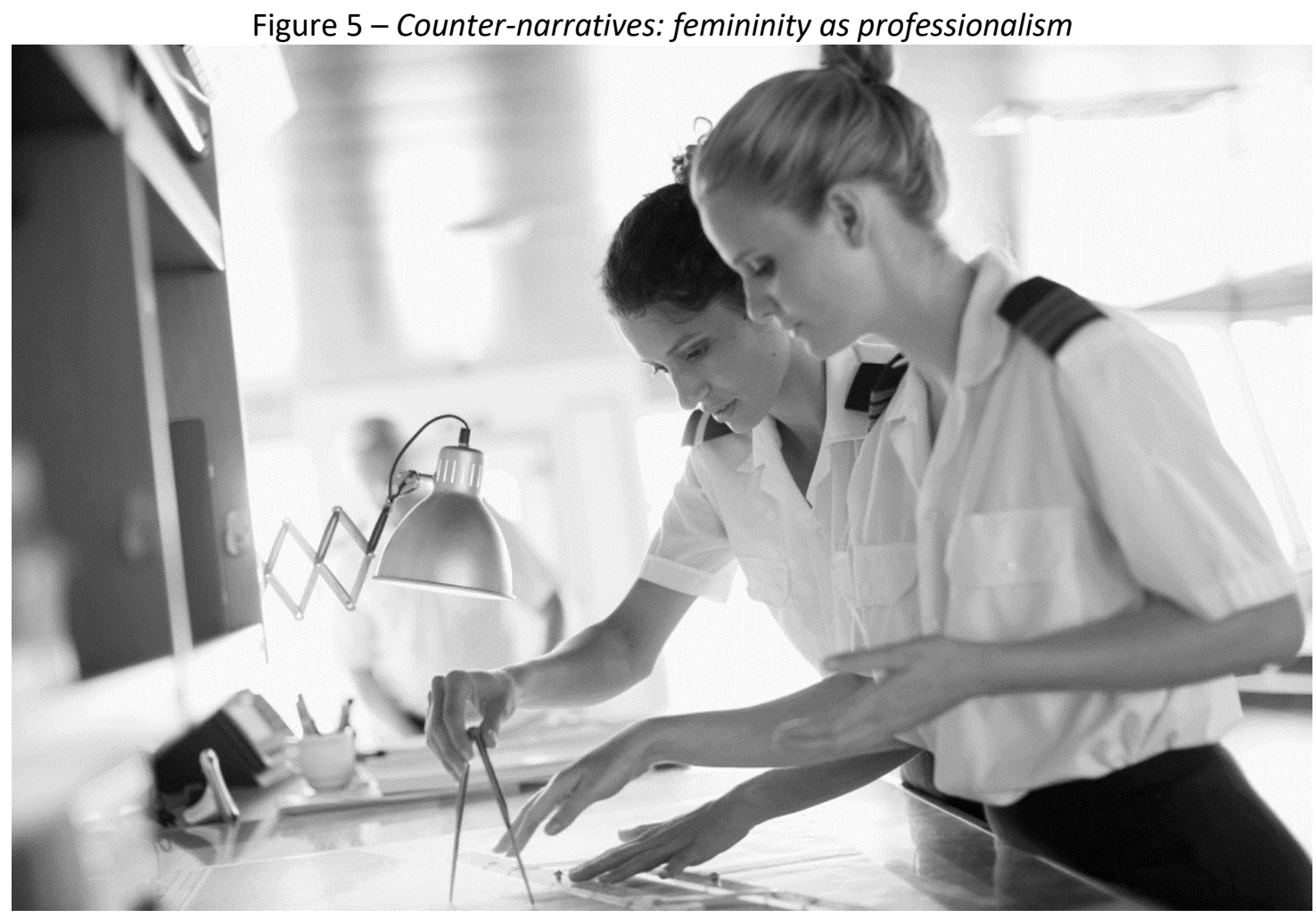

Source: MSC Cruises promotional brochures. Courtesy of Zero Creatives.

It is important to stress that the images of the workers have a very low level of sexualisation. Independently of their role, job, gender, hierarchical position within the staff, all the workers are dressed and displayed in ways which underplay their sexual dimension. Most probably, this is due to the need to emphasise their earnestness, but on a subtler level, this narrative helps in forging a divide between the client and the staff (cf. Vogel and Oschmann, 2013). The client is free to be a sexualised subject and to dream of sexualised subjects, while the staff are assumed to be 'external' to this sphere, being merely made up of 'servants' willing to move in order to satisfy the needs and desires of the clients. 


\subsection{Age}

The issue of age is crucial in cruise tourism. An old stereotype - that may be easily found in online forum discussions, usually presented as a distorted imagery - is that cruise tourism mainly targets elderly people, probably because of the possibility of travelling without moving. Of course, promotional materials build different narratives, insisting on the presence of lively young people, but at the same time elderly people are an important segment of the market, and hence many images play with narratives of happy ageing.

All cruise lines present the elderly subject in a rather uniform way: healthy, middle-class, white, heterosexual and good-looking. Most of the images display heterosexual couples, but in many cases images of people alone are displayed. It is interesting to consider an evident statistical imbalance: the number of photographs displaying only elderly females is less than half of the number of images featuring males alone. The case of young adults is the opposite, as the quasi-totality of the images in this category portray (sexualised) females. The implicit narrative is that the elderly subject travelling alone is typically male, while in the case of young people is female. This narrative echoes gendered stereotypes, which reinforce the male gaze: specifically, old women tend to be represented as desexualised, differently from old males. A classical stereotype analysed in the literature (Buunk et al., 2002), for example, is the idea that an old man's physical unattractiveness may be compensated by high social status, education, or income, and hence an old men may be attractive in the eyes of younger heterosexual women. In this sense, in these promotional images, elderly males always dress elegantly and consume status-symbol goods such as books and cigars (cf. Featherstone and Wernick, 1995). The masculine gaze may be detected also in the wide display of images showing hyper-active and dynamic aged men engaging with sports (Figure 6). Differently, elderly women mostly smile and drink, as sorts of static objects.

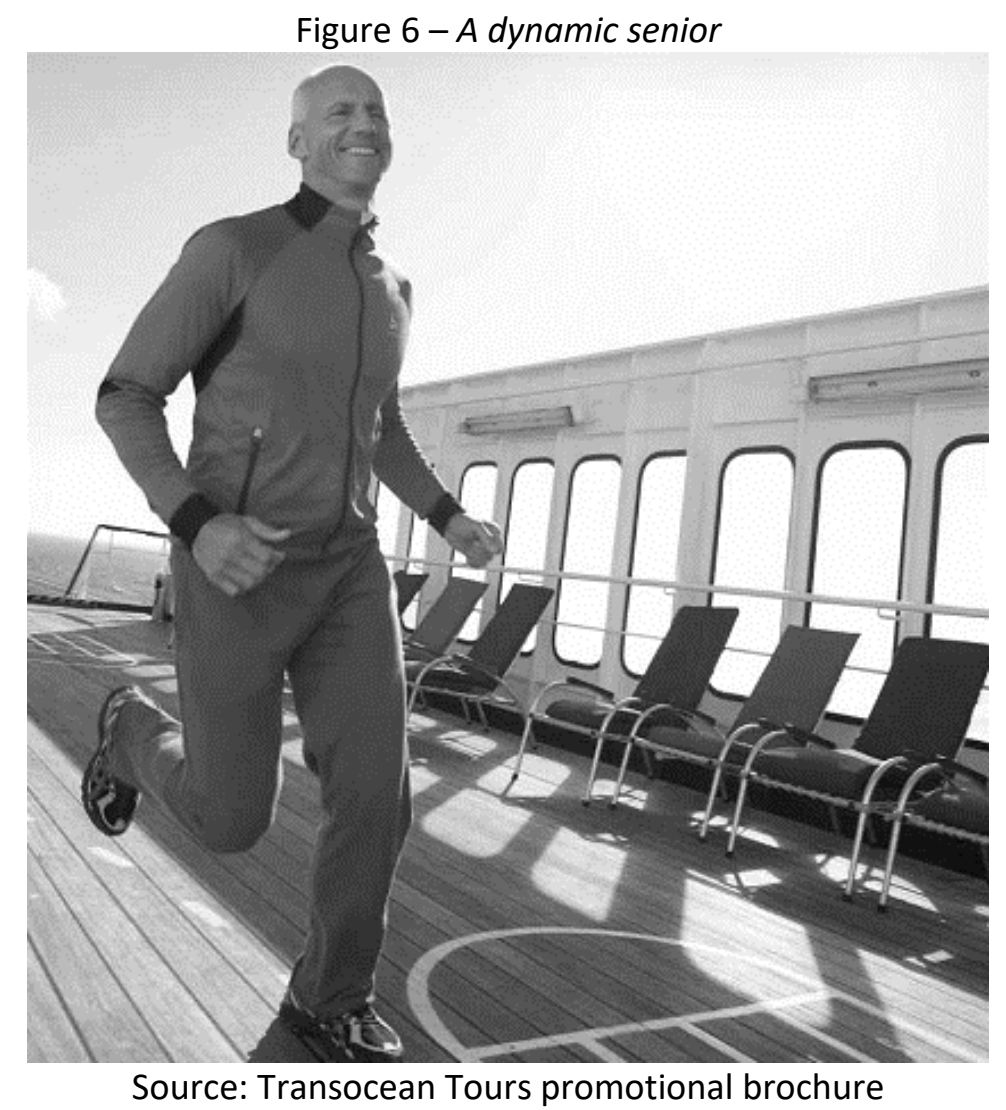




\subsection{Contact: natures and cultures}

The experience of the cruise is not supposed to develop entirely on board, but also externally, and particularly through excursions. In this case, mobility is crucial in building narratives of exploration and adventure. Particularly, it is useful to distinguish between two different themes: contact with nature and contact with 'other' cultures (where, of course, the nature vs culture dichotomy is a simplification in order to schematise the narratives: cf. Castree, 2005). Contact with nature is represented by nurturing ideas of adventure, particularly by displaying wild animals such as polar bears (cf. Picard, 2015). This is a pivotal representational element of cruise lines such as Hurtigruten, Norwegian Cruise, Orion, Quark Expeditions, Un-Cruise, and in specific themed cruises proposed for example by Hapag-Lloyd. Physical encounters with the environment and interactions with wildlife are, of course, two popular ingredients of tourism marketing (Waitt and Cock, 2007). Thus, animals are leveraged as physical beings that can be observed and interacted with through off-boat physical experiences, and as symbols of specific landscapes (cf. Hill et al., 2014).

In cultural theory, a large body of literature has stressed how contact with wildlife has been culturally constructed as a masculine domain, particularly in the framework of colonialist cultures and related grand-projects of 'exploring' and 'civilising' undomesticated spaces (in human geography, see particularly Whatmore, 2002). This traditional cultural construction is palpable in the promotional images of the cruise industry, as pictures presenting interaction between humans and animals privilege masculine subjects (see Figure 7).

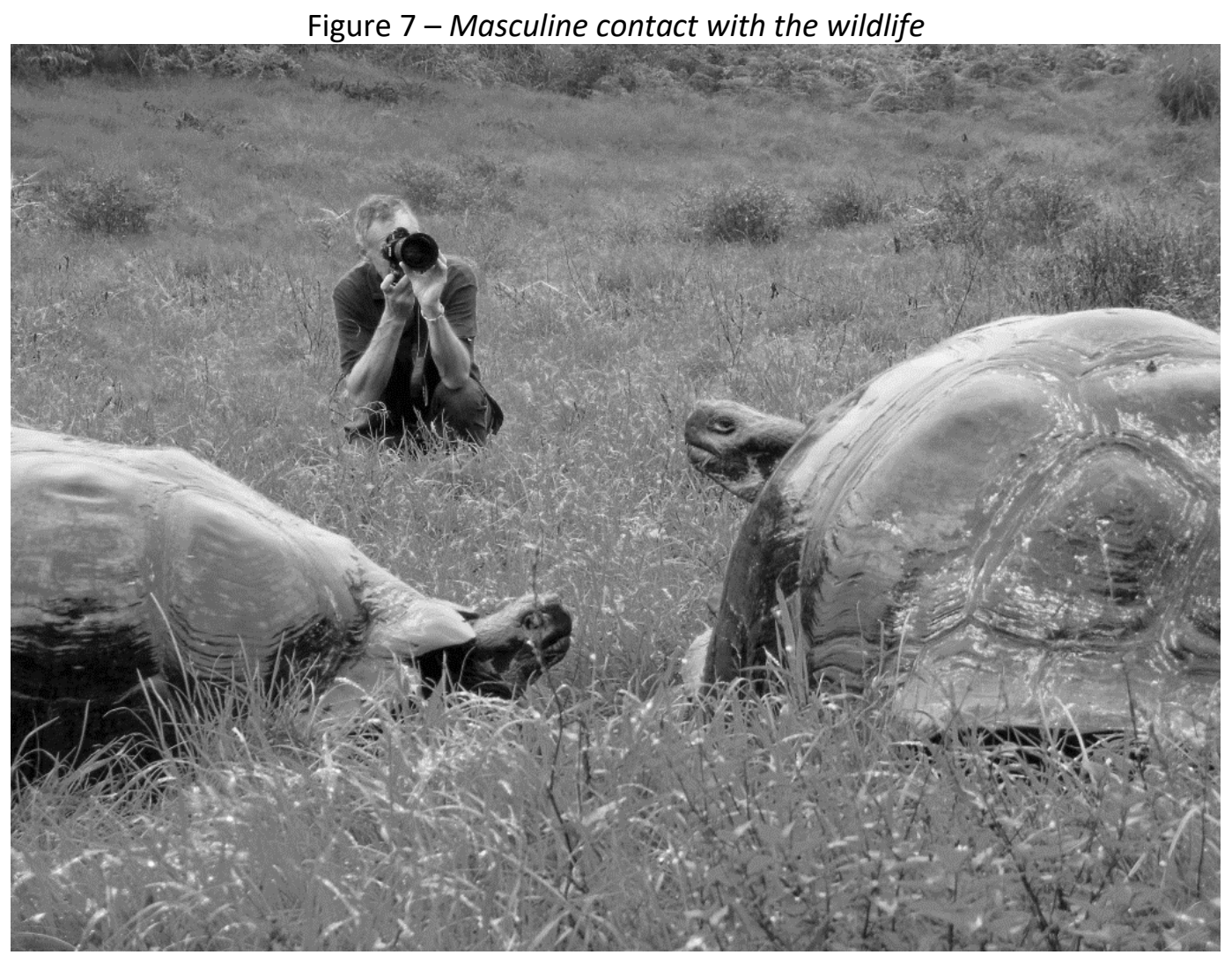

Source: Orion Expedition Cruises promotional brochure.

Courtesy of Stacy Sindlinger / Lindblad Expeditions 
Conversely, a meaningful narrative concerns the encounter with 'different' cultures. Several cruise lines, and particularly Aida, AmaWaterways, Azamara, Holland America, Paul Gaugin, P\&O and Viking cruises, display contact with the Other through representations of 'exotic' people wearing traditional local dress (at least from a Western perspective). Curiously, most of the images portraying people from 'exotic' parts of the world privileges feminine static subjects, which are supposed to be more sensual - as well as less 'dangerous' and 'unpredictable' - than mobile men (cf. Porter et al., 2010; Wilkes, 2013). Surely, this kind of narrative proposes a 'sanitised' experience of contact with the Other (Pratt, 2008), grounded in imagery that opposes 'mobile' tourists with the 'location-bound' and 'fixed' locals: as theorised in cultural geography (Duncan et al., 2013), the tourist, who is supposed to possess various forms of economic and cultural capital (resources, knowledge, abilities, cosmopolitan attitudes) is able to explore the worlds of the 'indigenous people', which are seen as immobile, untouched, and available to the mobile outsider (cf. Wilkes, 2013). The tourist/explorer is typically assumed to be male (possibly accompanied by women), further naturalising the idea that lonely women are 'out of place' when far from home, an idea critically reviewed by various critical scholars (for example, Rose, 1993; Cresswell, 1996). However, in line with another cultural stereotype discussed in the literature on consumption and gendered material cultures (for example by Shields, 1992, and more recently by Rabbiosi, 2014), lonely women are 'in place' when engaging with shopping in an urban setting, as shown in Figure 8 . In this sense, feminine subjects are culturally 'allowed' to leave the ship if directed towards urban 'civilised' spaces of consumption: Figure 8 is emblematic in displaying a frivolous, defenceless, and sexualised woman enjoying a walk off the ship.

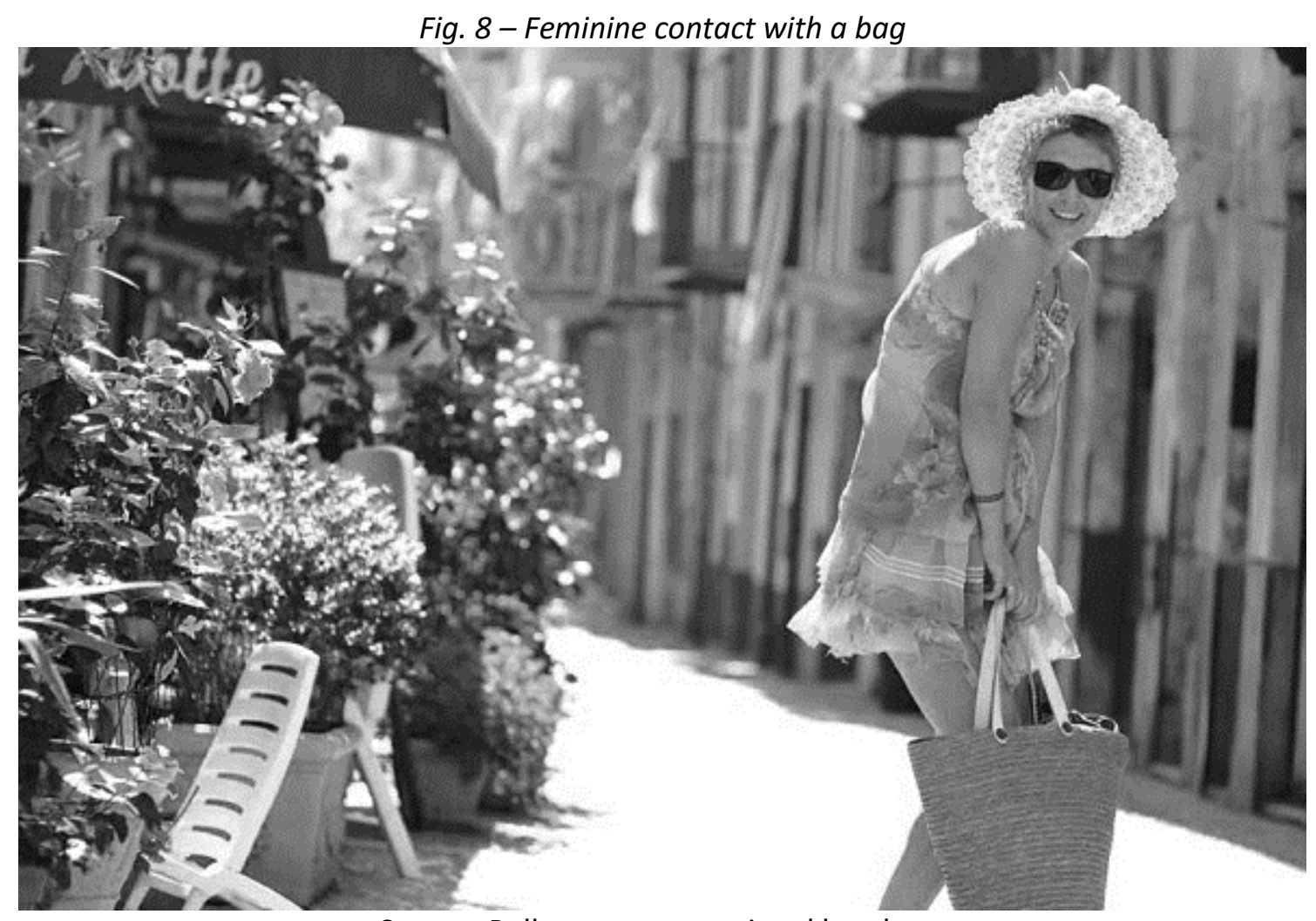

Source: Pullmantur promotional brochure 


\section{Concluding remarks}

This study analysed visual representations of cruise experiences, with a focus on gender and mobility, particularly by commenting on four thematic categories concerning issues related to pleasure, work, age, and contact with nature/culture.

The analysis confirms a core idea at the basis of many theories developed by feminist critical literature in cultural studies and social sciences: promotional images support and reproduce a masculine gaze, which naturalises gendered roles and stereotypes. Although the images of women enjoying cruises may apparently be decoded as elements of fair tourist narratives (as women enjoy a form of leisure similarly to men), a more careful observation allows to highlight the dominance of masculine cultural perspectives and discourses, confirming the relevance of the tourist sphere as a meaningful field for developing progressive and critical scholarship.

More specifically, the paper maps different narrative patterns mobilising ideas and representations of mobility and stativity within promotional discourses. This exercise reveals that there is not at all a simple and linear relation between positionality, gender, and representations of mobility: different ideas of feminine and masculine mobility are used in order to produce gendered discourses. Mobility and stativity, in fact, are not univocal symbols, as they may iconise and characterise different meanings in different contexts and situations, and hence it may be important for critical tourist studies to investigate the power of imaginaries of mobility in reproducing culturally uneven discourses: this paper has proposed an analysis focused on gender, but representations of mobility may potentially have a role in reproducing dominant and subaltern positionalities related to class, race, age, nationality, etc. In this sense, the paper aims at stimulating further researches on the cultural meanings of mobility in critical tourist studies.

Finally, the paper challenges the idea of movement as a univocal expression of agency and empowerment. The case of cruise tourism testifies to how movement and travelling may be both passive and active experiences, including a number of in-between experiences. Movement is not just the performance of motility, but it is also - among other things - an experience, a feeling, an aesthetic formation, and a predisposition: many of the images analysed in this paper show people doing things apparently disconnected from travelling in a strict sense, but at the same time all the images build on a narrative of travelling, a narrative that is definitely embedded in uneven power relations

\section{Bibliography}

Aitchison, C. 1999. New cultural geographies: the spatiality of leisure, gender and sexuality. Leisure Studies 18 (1), pp. 19-39.

Aitchinson, C. 2006. The critical and the cultural: explaining the divergent paths of leisure studies and tourism studies, Leisure Studies 25(4), pp. 417-422.

Aitchison, C. 2001. Theorizing Other discourses of tourism, gender and culture. Can the subaltern speak (in tourism). Tourist Studies 1 (2), pp. 133-147.

Aitchison, C, Macleod, N., Shaw, S. (eds.) 2002. Leisure and Tourism Landscapes: Social and Cultural Geographies. London: Routledge.

Aitchison, C. 2009. Gender and tourism discourses: advancing the gender project in tourism studies. In T. Jamal and M. Robinson (eds.), The Sage Handbook of Tourism Studies. London: Sage, pp. 631-644.

Anderson, K. 1996. Engendering race research. In N. Duncan (ed.), Bodyspace: Destabilizing Geographies of Gender and Sexuality. London: Routledge, 197-211.

Arend, P. 2014. Gender and advertising. In A. Trier-Bieniek and P. Leavy (eds.) Pop Culture. A TextReader. Rotterdam: Gender \&. Sense, pp. 53-79. 
Ateljevic, I., Morgan, N. and Pritchard A. 2007. Editors' introduction: promoting an academy of hope in tourism enquiry. In I. Ateljevic, A. Pritchard and N. Morgan (eds.), The Critical Turn in Tourism Studies: Innovative Research Methodologies. Amsterdam: Elsevier, pp. 1-8.

Atkinson, R. and Blandy, S. 2009. A picture of the floating world: grounding the secessionary affluence of the residential cruise liner. Antipode 41 (1), pp. 92-110.

Banks, M. 2001. Visual Methods in Social Research. London: Sage.

Bell, D. and Valentine, G. (eds.) 1995. Mapping Desire: Geographies of Sexualities. London: Routledge

Berger, A. 2004. Ocean Travel and Cruising: A Cultural Analysis. Binghamton (NY): Haworth Hospitality Press.

Bianchi, R. 2009. The 'critical turn' in tourism studies: a radical critique. Tourism Geographies 11 (4), pp. 484-504.

Boltanski, L. and Chiapello, È. 1999. Le nouvel esprit du capitalisme. Paris: Gallimard. English edition: The New Spirit of Capitalism. London: Verso, 2005.

Buunk, B., Dijkstra, P. Fetchenhauer, D. and Kenrick, D. 2002. Age and gender differences in mate selection criteria for various involvement levels. Personal Relationships 9 (3), pp. 271-278.

Cameron, J. and Gibson-Graham, J.K. 2003. Feminising the economy: metaphors, strategies, politics. Gender, Place and Culture 10 (2), pp. 145-157.

Castree, N. 2005. Nature. London: Routledge.

Chin, C. 2008. Cruising in the Global Economy: Profits, Pleasure and Work at Sea. Aldershot: Ashgate.

Clancy, M. 2008. Cruisin' to exclusion: commodity chains, the cruise industry, and development in the Caribbean. Globalizations 5 (3), pp. 405-418.

Clifford, J. 1997. Routes: Travel and Translation in the Late 20th Century. Cambridge, MA: Harvard University Press.

Connell, R. 2005. Masculinities. Berkeley: University of California Press.

Cresswell, T. 1996. In Place/Out Place. Geography, Ideology, and Transgression. Minneapolis: University of Minnesota Press.

Cresswell, T. 2010. Towards a politics of mobility. Environment and Planning D: Society and Space 28 (1), pp. 17-31.

Cresswell, T. and Uteng. T. 2008. Gendered mobilities: towards an holistic understanding. In T. Uteng and T. Cresswell (eds.), Gendered Mobilities. Aldershot: Ashgate, pp. 1-12.

Degen, M. and Wainwright, E. 2010 Wallpaper* City Guides and Gendering the Urban Aesthetic. Tourist Studies 10 (2), pp. 155-174.

Dickinson, B. and Vladimir, A. 2008. Selling the Sea. An Inside Look at the Cruise Industry. Hoboken: Wiley.

Domosh, M. and Saeger, J. 2001. Putting Women in Place: Feminist Geographers Make Sense of the World. New York: The Guilford Press.

Dowling, R. 2006. The cruising industry. In R. Dowling (ed.) Cruise Ship Tourism. Wallingford: CABI, pp. 317.

Duncan, N. 1996 Sexuality in public and private spaces. In N. Duncan (ed.), Bodyspace: Destabilizing Geographies of Gender and Sexuality. London: Routledge, pp. 127-145.

Duncan, T., Scott, D. and Baum, T. 2013. The mobilities of hospitality work: an exploration of issues and debates. Annals of Tourism Research 41, pp. 1-19.

Featherstone, M. and Wernick, A. (eds.) 1995. Images of Aging. Cultural Representations of Later Life. London: Routledge.

Frohlick, S. and Johnston, L. 2011. Naturalizing bodies and places: tourism media campaigns and heterosexualities in Costa Rica and New Zealand, Annals of Tourism Research 38 (3), pp. 10901109.

Ganser, A. 2009. Roads of Her Own. Gendered Space and Mobility in Americam Women's Road Narratives, 1970-2000. New York: Rodopi.

Gibson, P. 2006. Cruise Operations Management. Oxford: Elsevier.

Gill, R. 2009. Beyond the 'sexualization of culture' thesis: an intersectional analysis of 'sixpacks', 'midriffs' and 'hot lesbians' in advertising. Sexualities 12 (2), pp. 137-160.

Goffman, E. 1976. Gender Advertisements. New York: Harper \& Row.

Haldrup, M. and Larsen, J. 2010. Tourism, Performance and the Everyday: Consuming the Orient. London: Routledge. 
Harris, C. and Ateljevic, I. 2003. Perpetuating the male gaze as the norm: challenges for 'her' participation in business travel. Tourism Recreation Research 28 (2), pp. 21-30.

Hasty, W. and Peters, K. 2012. The ship in geography and the geographies of ships. Geography Compass 6 (11), pp. 660-676.

Hill, J., Curtin, S. and Gough, G. 2014. Understanding tourist encounters with nature: a thematic framework. Tourism Geographies 16 (1), pp. 68-87.

Hung, K. and Petrick, J. 2011. Why do you cruise? Exploring the motivations for taking cruise holidays, and the construction of a cruising motivation scale. Tourism Management 32 (2), pp. 386-393.

Hughes, H. 2006. Lesbians as tourists: poor relations of a poor relation. Tourism and Hospitality Research 7 (1), pp. 17-26.

Jaakson, R. 2004. Beyond the tourist bubble? Cruiseship passengers in port. Annals of Tourism Research 31 (1), pp. 44-60.

Johnston, L. 2001. (Other) Bodies and tourism studies. Annals of Tourism Research 28 (1) pp. 180-201.

Jokela, S. and Raento, P. (2012), Collecting visual materials from secondary sources. In T. Rakić and D. Chambers (eds.), An Introduction to Visual Research Methods in Tourism. New York: Routledge, pp. 53-69.

Kinnaird, V. and Hall, D. (eds.) 1994. Tourism: A Gender Analysis. London: Belhaven.

Klein, R. 2002. Cruise Ship Blues. The Underside of the Cruise Industry. Gabriola Island: New Society.

Kwortnik, R. and Rand, J. 2012. Marketing communications in the cruise industry. In M. Vogel, A. Papathanassis and B. Wolber (eds.), The Business and Management of Ocean Cruises. Wallingford: CABI, pp. 117-130.

Massey, D. 1994. Space, Place and Gender. Minneapolis, MN: University of Minnesota Press.

McDowell, L. 2005. The men and the boys. Bankers, burger makers and barmen. In B. Van Hoven and K. Hörschelmann (eds.), Spaces of Masculinities. London: Routledge, pp. 17-27.

Mulvey, L. 1975. Visual and other pleasures. Screen 16 (3), pp. 6-18.

Papathanassis, A., Lukovic, T. and Vogel, M. (eds.) 2012. Cruise Tourism and Society. A Socio-economic Perspective. Heidelberg: Springer.

Picard, D. 2015. White magic: an anthropological perspective on value in Antarctic tourism. Tourist Studies 15 (3), pp. 300-315.

Pink, S., Kürti, L. and Afonso, A. (eds.) (2004). Working Images. Visual Research and Representation in Ethnography. London: Routledge

Porter, G., Hampshirea, K., Abaneb, A., Robsonc, E., Munthalic, A., Mashirid, M. and Tanleb. A. 2010. Moving young lives: mobility, immobility and inter-generational tensions in urban Africa. Geoforum 41 (5), pp. 796-804.

Pratt, M. 2008. Imperial Eyes: Travel Writing and Transculturation. London: Routledge.

Pritchard, A. 2001. Tourism and representation: a scale for measuring gendered portrayals. Leisure Studies 20 (2), pp. 79-94.

Pritchard, A. and Morgan, N. 2000. Privileging the male gaze. Gendered tourism landscapes. Annals of Tourism Research 27 (4), pp. 884-905.

Pritchard, A. and Morgan, N. 2005. 'On location'. Re(viewing) bodies of fashion and places of desire. Tourist Studies 5 (3), pp. 283-302.

Pritchard, E. 2000. The Way Out West: Development and the Rhetoric of Mobility in Postmodern Feminist Theory. Hypatia 15 (3), pp. 45-72.

Puar, J. 2002. A transnational feminist critique of queer tourism. Antipode 34 (5), pp. 935-946.

Rabbiosi, C. 2014. The condition of 'Cosmo-housewives': leisure shopping, the mainstream and its ambiguities. Gender, Place \& Culture 21 (2,) pp. 211-227.

Rodrigue, J.-P. and Notteboom. T. 2013. The geography of cruises: itineraries, not destinations. Applied Geography 38, pp. 31-42.

Rose, G. 1993. Feminism and Geography. The Limits of Geographical Knowledge. Cambridge: Polity Press.

Rose, G. 2012. Visual Methodologies. An Introduction to Researching with Visual Materials (3rd edition). London: Sage.

Sather-Wagstaff, J. 2012. Beyond content: thematic, discourse-centred qualitative methods for analysing visual data. In T. Rakić and D. Chambers (eds.), An Introduction to Visual Research Methods in Tourism. New York: Routledge, pp. 169-186. 
Scarles, C. 2004. Mediating landscapes: The processes and practices of image construction in tourist brochures of Scotland. Tourist Studies 4 (1), pp. 43-67.

Scarles, C. 2010. Where words fail, visuals ignite: Opportunities for visual autoethnography in to urism research. Annals of Tourism Research 37 (4), pp. 905-926.

Scarles, C. 2014. Tourism and the visual. In A.A. Lew, C.M. Hall and A. M. Williams (eds.), The Wiley Blackwell Companion to Tourism. Chichester: Wiley, pp. 325-335.

Schmid, K. 2008. Doing ethnography of tourist enclaves: Boundaries, ironies, and insights. Tourist Studies $8(1)$, pp. 105-121.

Shields, R. (eds.) 1992. Lifestyle Shopping. The Subject of Consumption. London: Routledge.

Sirakaya, E. and Sonmez, S. 2000. Gender images in state tourism brochures: an overlooked area in socially responsible tourism marketing. Journal of Travel Research 38 (4), pp. 353-362.

Terry, W. 2011. Geographic limits to global labor market flexibility: the human resources paradox of the cruise industry. Geoforum 42 (6), pp. 660-670.

Thurnell-Read, T. and Casey, M. (eds) 2014. Men, Masculinities, Travel and Tourism. Basingstoke: Palgrave Macmillan.

Vogel, M and Oschmann, C. 2013. Cruising through liquid modernity. Tourist Studies 13 (1), pp. 62-80.

Vogel, M., Papathanassis, A. and Wolber, B. (eds.) 2012. The Business and Management of Ocean Cruises. Wallingford: CABI.

Waitt, G., and Cook, L. 2007. Leaving nothing but ripples on the water: performing ecotourism natures. Social \& Cultural Geography 8 (4), pp. 535-550.

Waitt G., Markwell, K. and Gorman-Murray, A. 2008. Challenging heteronormativity in tourism studies: locating progress. Progress in Human Geography 32(6), pp. 781-800.

Weaver, A. 2005a. Interactive service work and performative metaphors. The case of the cruise industry. Tourist Studies 5 (1), pp. 5-27.

Weaver, A. 2005b. Spaces of containment and revenue capture: 'super-sized' cruise ships as mobile tourism enclaves. Tourism Geographies 7 (2), pp. 165-184.

Weaver, A. 2011. The Fragmentation of Markets, Neo-Tribes, Nostalgia, and the Culture of Celebrity: The Rise of Themed Cruises. Journal of Hospitality and Tourism Management 18 (1), pp. 54-60.

Whatmore, S. 2002. Hybrid Geographies. Natures, Cultures, Spaces. London: Sage.

Wilkes, K. 2013. From the landscape to the White female body: representations of postcolonial luxury in contemporary tourism visual texts. In J.A. Lester and C. Scarles (eds.), Mediating the Tourist Experience. From Brochures to Virtual Encounters. Farnham: Ashgate, pp. 33-56.

Young, I. 2005. On Female Body Experience: 'Throwing Like a Girl' and Other Essays. New York: Oxford University Press. 